\title{
Dos décadas de cooperación europea en Chile: una asociación para el desarrollo
}

\author{
"Two decades of European Foreign Aid in \\ Chile: an association for the Development"
}

\author{
Beatriz Hernández* \\ Pierre Lebret**
}

\begin{abstract}
RESUMEN
El estudio se centra en la evolución de la cooperación al desarrollo desde principios de la década de los años noventa en Chile, ya que representa un modelo exitoso de cooperación gracias a los cambios económicos y políticos que permitieron la firma del Acuerdo de Asociación (AA) en el año 2002. Como instrumento político de la UE, la cooperación en Chile se ha centrado tradicionalmente en el fortalecimiento institucional y la reducción de la pobreza con el fin de fomentar el desarrollo económico y mejorar los compromisos internacionales del país. En el último decenio, la ayuda oficial al desarrollo (AOD) ha dado una mayor prioridad a los proyectos de cohesión social, lo que refleja un cambio significativo en la estrategia europea de cooperación. Concluimos que la cooperación europea ha influido en el fortalecimiento de una institucionalidad y la concepción de políticas públicas más acordes con las necesidades de superación de las desigualdades y de representación ciudadana, y el fomento de la cooperación sur-sur y triangular como complementaria a la cooperación horizontal.
\end{abstract}

Académica Universidad Diego Portales, Doctora en Estudios Europeos. beatriz.hernandez@ udp.cl. Recibido: 5 de abril de 20I8. Aceptado: 27 de agosto de 2018.

** Magíster en Cooperación Internacional, ex Asesor de la Agencia Chilena de Cooperación Internacional para el Desarrollo y de la cepal.pierre.lebret2I@gmail.com 
Palabras Clave: Chile - Unión Europea - Ayuda al Desarrollo Cohesión Social - Cooperación Sur-Sur.

\begin{abstract}
This paper analyzes the evolution of EU development cooperation since the early 1990s in Chile because it represents a successful and advanced type of cooperation partnership. This association is explained by Chilean political and economic changes, resulting in the signing of an Association Agreement (AA) in 2002. As a political instrument, cooperation in Chile traditionally has focused on institutional strengthening capacity and poverty reduction, thus helping the country to foster economic development and to deepen international engagements. Recently, EU official assistance (OA) has prioritized social cohesion projects, reflecting the European development strategy. We conclude that the European Foreign Aid has been an influence on the institutional strengthening and public policies that responds to inequality challenges and social participation and the promotion of South-South and Triangular cooperation that complements the horizontal one.
\end{abstract}

Keywords: Chile - European Union - Foreign Aid - Social Cohesion - South-South Cooperation. 


\section{i. La Cooperación al desarrollo europeo hacia América Latina y Chile}

La Unión Europea es reconocida como un actor del sistema internacional desde los años ' 70 , gracias a una mayor presencia y capacidad de acción en países terceros a través del comercio; de la cooperación al desarrollo y ayuda humanitaria, y en tiempos más recientes, del diálogo político y las negociaciones para la resolución de conflictos.

François Duchêne denominó a la UE como un "civilian power", ya que persigue objetivos de política exterior usando medios políticos y económicos de carácter civil -es decir, no militares-, en una especie de acción colectiva que expresa los valores y características de la Comunidad (Bretherton y Vogler, 2006: 4I). Igualmente para Sanahuja (2007), "en las relaciones internacionales, la UE actúa como 'potencia civil' que trata de promover ciertos valores en su acción exterior, como los propios de su modelo de integración, que combina liberalización $y$ cohesión social y territorial".

La Ayuda Oficial al Desarrollo (AOD) se entiende como "el conjunto de políticas diseñadas y ejecutadas por actores públicos y privados de distintos países, que buscan promover un progreso más justo y equilibrado en el mundo, con el objetivo de construir un planeta más seguro y pacífico" (Gómez y Sanahuja, 1999: I7). La UE y sus Estados Miembros son, en conjunto, el mayor donante de AOD en el mundo, con un $52 \%$ de la ayuda total y un presupuesto comunitario de $\mathrm{I} 4,86$ billones de euros (Comisión Europea, 20I5a) que alcanza los 56 billones si se suman los países miembros (Comisión Europea, 2015b).

La política de cooperación económica es un instrumento que fortalece la diplomacia europea, permitiéndole hablar con una sola voz en la escena internacional. Esta se divide en 4 políticas prioritarias con fondos destinados a: I) ampliación a nuevos países; 2) vecindad (países vecinos); 3) socios estratégicos, y 4) cooperación al desarrollo. La cooperación con los países latinoamericanos se ha venido desarrollando en base a esta última política, ya que se concentra en áreas geográficas lejanas, que tienen grandes necesidades para alcanzar los Objetivos del Milenio.

América Latina y el Caribe solo representaba el 9,I\% de los fondos europeos en la década de los años 90, disminuyendo hasta el 7,5\% en los años 200I-20II, ya que los países miembros disminuyeron su ayuda dejándole un mayor protagonismo a la UE (Durán et al, 2013). No obstante, la UE y sus Estados Miembros siguen siendo el principal donante en la región con un $47 \%$ de la aOd total, como podemos ver en el siguiente gráfico. 


\section{GRÁFICO I}

AOD total comparado de los 3 donantes principales en América Latina

(US Dólar, millones) ${ }^{1}$

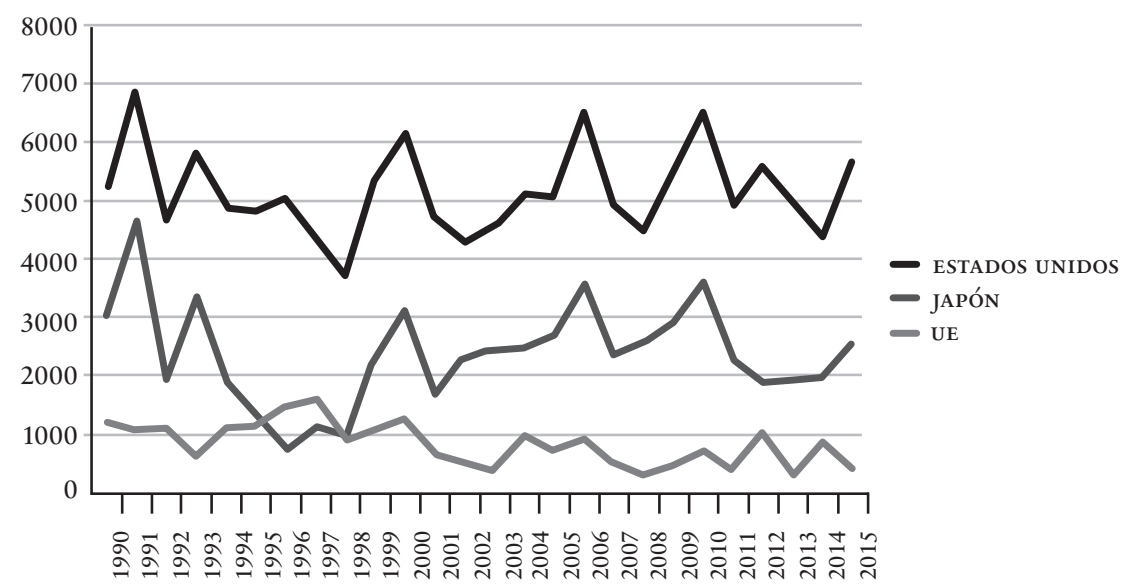

Fuente: Elaboración propia con datos del CAD, OCDE $20 \mathrm{I7}$

En América Latina las orientaciones de la Ayuda al Desarrollo se definen en los Documentos Estratégicos Regionales (DER), Subregionales y por país (DEP) que son bilaterales. La UE ha considerado la región como un bloque geográfico estratégico que comparte problemas y desafíos que pueden ser trabajados de forma coordinada entre los países latinoamericanos.

De acuerdo al alcance geográfico, la programación regional tiene sus propios intereses estratégicos y programas sectoriales, siendo el sector de recursos humanos y entendimiento mutuo el

1 La información respectiva a la Unión Europea es el conjunto de la ayuda de las instituciones europeas, más cincos países miembros: Francia, España, Italia, Luxemburgo y Países Bajos. más importante, con un 40\% de los fondos, seguido por el de cohesión social con un $35 \%$ y el de integración y comercio que alcanza un $25 \%$ (Comisión Europea, 2007: 29). A nivel bilateral, el desarrollo y la cohesión social representan el $56 \%$ de las ayudas europeas, siendo un porcentaje superior a las ayudas regionales, aunque presenta variaciones según las necesidades de los países (Durán et al, 2013:90).

En cuanto a las relaciones de la Unión Europea y Chile, estas se remontan a los años ' 80 , cuando este país andino era receptor de la cooperación al desarrollo y beneficiario del Sistema Generalizado de Preferencias (SGP). Pero en 1996 Chile era un país con una democracia aparentemente consolidada y con el régimen comercial más 


\section{GRÁFICO 2}

Comparativos de la AOD Multilateral de 2000-2015 en millones de dólares

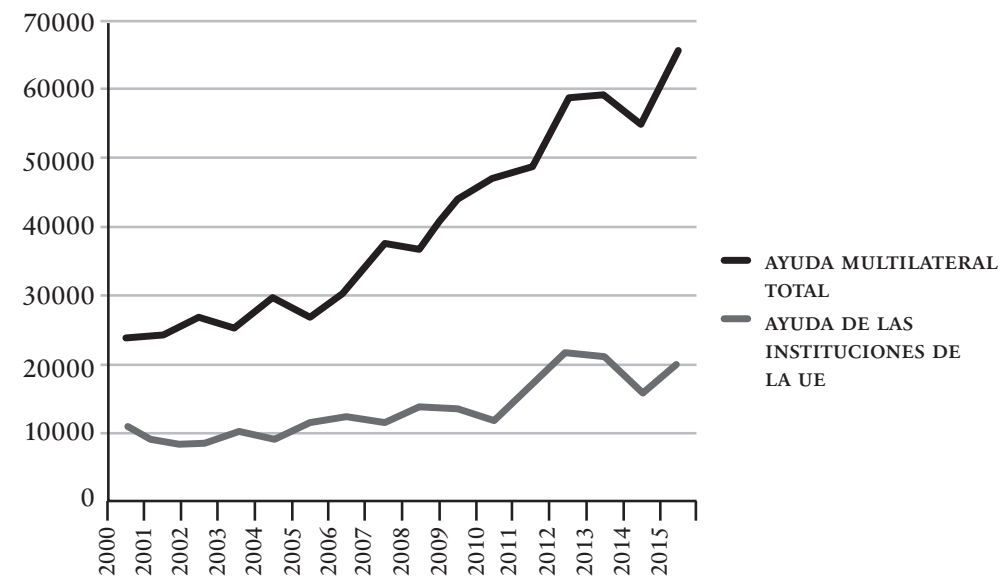

Fuente: Elaboración propia a partir de los datos de la oCDE (OCDE.Stat 20I5)

abierto de toda América Latina. Las relaciones se profundizaron ese mismo año, al firmar un Acuerdo Marco de Cooperación, con el objetivo de llegar a una plena Asociación Económica y Política entre la UE y Chile.

Es en este contexto de relaciones económicas bilaterales que se abrieron oficialmente las negociaciones en 1999, como un paso más avanzado al apoyo que la Comunidad y los países miembros habían otorgado a la liberalización comercial y reestructuración económica de Chile ${ }^{2}$. Entre los años 1990 y 2013 , se puede observar que la ayuda de la Unión Europea hacia

2 Consejo Europeo. SN3226/3/99 REV 3 (AMLAT). Directrices de Negociación para nuevos acuerdos con MERcosur y Chile.
Chile como organismo multilateral, ha sido una de las principales fuentes de financiación de proyectos de cooperación para el desarrollo nacional. A partir del año 2000, la UE aumentó su porcentaje de cooperación hacia Chile, representando la mayoría de la ayuda multilateral en el país. Sin duda, la firma del Acuerdo de Asociación favoreció el incremento de la ayuda europea para suavizar la fuerte asimetría institucional y comercial entre los socios. Cabe señalar que el aumento de la ayuda entre el año 2010 y 20I2, que se aprecia en el gráfico 2, está relacionado con la ayuda humanitaria de la Oficina Europea de Ayuda Humanitaria (есно) tras el terremoto del año 20ro. Para efectos de las estadísticas del Comité de Ayuda al 
Desarrollo (CAD) de la OCDE, se suma la ayuda humanitaria a la Ayuda Oficial al Desarrollo (AOD).

Este artículo explica la evolución de la cooperación al desarrollo de la UE hacia Chile, tomando como factores los cambios que se reflejaron en el país andino desde principios de los años noventa y los intereses europeos de extender su modelo social en la región latinoamericana. En un principio, la cooperación estuvo más asociada a los intereses europeos en fortalecer el Acuerdo de Asociación con el que se pueden apreciar impactos más visibles en los aspectos comerciales y de manera más reciente en la ayuda a la cohesión social. A pesar del limitado presupuesto, la AOD ha sido significativa, influyendo en la formación de políticas sociales y el fortalecimiento de la institucionalidad en el país. Se puede concluir que la política de la UE de "graduar" a Chile como un país que ya no necesita ayuda al desarrollo, es una decisión que responde a una coyuntura de crisis más que a una evaluación positiva del desarrollo del país, ya que siguen persistiendo importantes desafíos de equidad y cohesión social.

Para esto se hará una revisión de la evolución y estrategias de la AOD a partir de la financiación y número de actividades realizadas en Chile, para lograr mayores niveles de cohesión social, y fortalecer las políticas públicas y las instituciones tanto en la modalidad bilateral como regional.

\section{El Acuerdo de Asociación entre Chile y la Unión EUROPEA: ¿UN CAMBIO EN LA COOPERACIÓN?}

La importancia del Acuerdo de Asociación firmado en el año 2002 radica en que incluye cooperación en diversas áreas como la económica, científica y tecnológica, cultural, medioambiental y social. Estos puntos tendrían como finalidad "el fortalecimiento y la promoción del desarrollo social, del desarrollo económico y de la protección del medio ambiente, al mismo tiempo que otorgan una prioridad particular al respeto de los derechos sociales fundamentales" (Blanc, 2005: 83). Sin embargo, casi todo el presupuesto de la cooperación $(65 \%)$ se ha destinado a proyectos comerciales y empresariales. Como indica Jordán, la orientación de esta cooperación económica era llegar a un estadio más avanzado en el que "la ayuda es en beneficio mutuo del donante y del beneficiario, pero enfocada especialmente al sector privado" (Jordán, 2005: 25I).

Como en el año 2002 Chile ya era un país de renta media, el Acuerdo de Asociación incluye un Fondo llamado de costos compartidos. Por primera vez, el gobierno de Chile financia el 50\% de los costos de los proyectos que forman parte de su estrategia de 
intervención pública ${ }^{3}$. Los países de Renta Media son aquellos que "han logrado avanzar en el área de desarrollo y bienestar social, estabilidad democrática, diversidad cultural y política, fortaleza de las instituciones y estabilidad en sus políticas públicas" (Lazo, 2013, 370).

Entre los proyectos más importantes están los de apoyo a la creación y desarrollo de empresas innovadoras (22 millones de euros). El objetivo de los proyectos era contribuir al aumento de la competitividad de la economía chilena mediante el apoyo a la innovación y al desarrollo tecnológico en áreas estratégicas de la economía nacional y a su transferencia y difusión en el sector empresarial, especialmente entre las pequeñas y medianas empresas (pymes), para mejorar el posicionamiento competitivo nacional e internacional. También incluye proyectos complementarios en educación para el emprendimiento (Delegación de la UE en Chile y AGCID, 20I2).

A partir del año 2003, rige el Acuerdo de Asociación Política, Económica y de Cooperación entre Chile y la Unión Europea (AA), suscrito en noviembre de 2002. Este último promueve la participación de Chile en

3 Chile es un país de renta media alta por lo que dejó de ser sujeto receptor de Ayuda Oficial al Desarrollo (AOD) sin retorno, es decir que pasa a financiar conjuntamente los proyectos de ayuda bilateral, multilateral o triangular de los organismos internacionales o países de la ocDE. Ver Índices de Desarrollo Humano 2002 en adelante y el Informe de 2013 del PNUD. materia de cooperación, posicionándolo como un "país asociado" en la aplicación de la cooperación de la Unión Europea y, por tanto, por primera vez podían participar en programas europeos como el Horizonte 2020 y en la financiación del Banco Europeo de Inversiones (BEI).

La modalidad principal por la que se aplica la cooperación bilateral es de tipo económica, a través de fondos que financian proyectos socioeconómicos y becas para alumnos de educación superior (Erasmus Mundo). A su vez, la cooperación técnica también está presente, enfocada en generar diálogos sectoriales en las áreas prioritarias de la cooperación (educación, empleo, energía).

Durante el período 2002-2006 se genera una mayor sistematización de la cooperación. No solo por la separación plurianual, sino por la claridad de los objetivos y de las áreas que tiene la cooperación.

Los aportes financieros de la cooperación de la UE constituyen un complemento a los programas que desarrolla el Gobierno en sus sectores prioritarios de intervención. En este contexto, el Programa de Cooperación UE-Chile para el período 2000-2006 contó con un aporte de la UE de 34.4 millones de euros y un aporte equivalente por parte del Gobierno de Chile, cumpliendo así con los principios que estableció el acuerdo suscrito en el año 2002.

En este período, los proyectos se centraron principalmente en la aplicación del Acuerdo de Asociación. Esta 
prioridad se ve reflejada en el Programa Fondo de Aplicación del AA, ya que como indica Ricardo Herrera, "se ejecutaron proyectos que tenían como objetivos el fortalecimiento de la institucionalidad normativa, generar capacidades, armonizar procedimientos con la UE, así como fortalecer procesos y soportes tecnológicos que ayudaran a facilitar el funcionamiento del sector público chileno" (Herrera, 20II: 49).

La Declaración de París sobre "La Eficacia de la Ayuda", suscrita en 2005 por más de cien países, acordó una relación más horizontal en la que los países receptores pasan a llamarse "socios", cumpliendo varios principios de corresponsabilidad. De acuerdo a Martínez y Sanahuja (2009), "son los países socios los que definen - en principio- sus propias estrategias de desarrollo mediante procesos consultivos con los donantes y participación de la sociedad civil y del sector privado". Estos compromisos internacionales cambiaron la forma de planificar y gestionar la cooperación con Chile para el siguiente ciclo o estrategia de ayuda al desarrollo.

\section{La Estrategia 2007-2013: una nueva etapa de la cooperación}

Durante el segundo período 200720I3, la cooperación se sigue rigiendo con los mismos acuerdos que el rango anterior, contando con un financiamiento de la Comisión Europea de 4I millones de euros.
A diferencia del período anterior, que se concentró en el fortalecimiento del sector público y privado para mejorar el comercio, los objetivos planteados en la Estrategia de Acción en Chile para el período 2007-2013, los beneficios del desempeño económico del país debían ser repartidos en términos de equidad e igualdad social. Es decir, el objetivo es alcanzar una sociedad más cohesionada, por lo que se financiarían proyectos e iniciativas orientadas a mejorar el acceso al empleo, la salud, la educación y la justicia, así como a reducir la desigualdad de género, minorías étnicas y regionales ${ }^{4}$. Estos objetivos respondían mejor a las necesidades del país, pero también al cumplimiento de la Objetivos del Milenio 2000-2015.

En el Plan Estratégico 2007-20I3, se recoge la prioridad de la UE, que es la

4 Desde el año 2005 la UE y Chile lanzaron diálogos sectoriales en torno a dos temas de interés mutuo: la educación y las políticas sociales. En marzo de 2005 se realizó la primera reunión del diálogo sectorial sobre educación superior, formación profesional y aprendizaje de idiomas. Luego, en septiembre de ese mismo año, tuvo lugar en Santiago el primer diálogo sectorial UE-Chile sobre políticas de empleo. En el marco de este diálogo sectorial también se realizó, el 22 de marzo de 2007, en Bruselas, un seminario-taller sobre políticas de empleo público, con la participación del Ministro de Trabajo de Chile y altos funcionarios de la Comisión Europea. En: Observatorio Social de las Relaciones UE-América Latina, www.observatorioueal-alop.eu. Además, en 2009, 20II y 2012 se han realizado diálogos sectoriales sobre Derechos Humanos. 
cohesión social, prioridad ampliamente discutida en los foros regionales, como son las Cumbres Presidenciales entre la Unión Europea y América Latina y el Caribe, sobre todo en la de Guadalajara en el año 2004, cuando se crea el programa Regional EUROsociAL. Es en esta línea que también en el presupuesto del fondo conjunto se iguala, por primera vez, la cooperación económica al sector empresarial y la cooperación en cohesión social, siendo los dos pilares de la cooperación (cuadro I).

CUADRO I

Líneas de Cooperación UE-Chile 2007-2013 (En millones de Euros)

\begin{tabular}{|l|c|c|c|}
\hline SECTOR DE LA COOPERAción & $\mathbf{2 0 0 7}$ & $\mathbf{2 0 1 1 - 2 0 1 3}$ & TOTAL \\
\hline I. Cohesión Social & 10.250 & 6.150 & 16.400 \\
\hline $\begin{array}{l}\text { 2. Educación: Intercambios } \\
\text { Académicos y Becas }\end{array}$ & 4.920 & 3.280 & 8.200 \\
\hline 3. Innovación y Competitividad & 10.250 & 6.150 & 16.400 \\
\hline Total & 25.420 & 15.580 & 41.000 \\
\hline
\end{tabular}

Fuente: Country Strategic Paper Chile 2007-2013, Comisión Europea.

\section{Proyectos influyentes en Chile}

Dado el escaso éxito para mejorar los índices del coeficiente Gini, que es 0,46 (OCDE, 20I5), y la importancia que ha adquirido en los últimos años la reducción de la pobreza y desigualdad en la relación de la Unión Europea y América Latina, la cohesión social se definió como uno de los objetivos importantes en la estrategia programática en la relación bilateral de Chile y la UE.
Aunque la cohesión social es un concepto muy amplio, se definiría como "la capacidad de una sociedad de asegurar el bienestar de todos sus ciudadanos, minimizando las disparidades y evitando la polarización. Una sociedad cohesionada es una comunidad que se apoya mutuamente en individuos libres que persiguen estos mismos objetivos por medios democráticos" (Consejo de Europa, 2004). 
En este sentido, la cooperación bilateral en el ámbito de cohesión social se "centrará en apoyar experiencias de políticas públicas y sociales adecuadas para una redistribución equitativa, un mejor acceso a la salud, a la educación, al empleo, la protección social y la justicia, como instrumentos adecuados para lograr una sociedad más justa y cohesionada" (CELARE, 2008). La promoción de la cohesión social ha sido implementada en Chile a través de diversos programas. Pero es importante señalar que la cooperación europea ha sido clave en la mejora de proyectos asociados al Ministerio de Salud, al Servicio Nacional de la Mujer (sernam), y al Ministerio de Planificación (MIDEPLAN), entre otros.

Por una parte se encuentra el Programa EUROsocial (programa regional), en el que existen 7 sectores estratégicos que abarcan ámbitos de la cohesión social ${ }^{5}$. Chile ha participado en diversos consorcios como el "Centro de Estudios de Justicia de las Américas" en el Consorcio del sector justicia, y en el "Fondo Nacional de Salud de Chile" en el sector salud.

Adicionalmente, se encuentra el "Programa de Apoyo a la Cohesión Social en Chile 2007-2010" (programa bilateral) que financió la implementación de 7 proyectos y 12 acciones directas específicas (AGCID, 20I3). El foco de este programa ha sido puesto

5 Los sectores de actuación son: empleo, justicia, salud, educación, fiscalidad, seguridad y gobernabilidad. en la protección social y el empleo con diversas instituciones públicas ${ }^{6}$. El objetivo era focalizar la ayuda a través de este programa a los grupos más vulnerables, y de acuerdo a la experiencia europea, influir en el desarrollo de políticas públicas en pro de mayor igualdad y reducción de la pobreza.

Los proyectos incluyen la dimensión de género y educación, focalizando ese ámbito en la calidad. Los montos del programa para el período 2007-20I0, 20II-20I3 se elevan a 20,5 millones de euros y 15,6 respectivamente, repartido en partes iguales entre la UE y Chile. Las iniciativas están orientadas a mejorar la participación de grupos vulnerables y el respeto de sus derechos, como: garantizar la consulta y participación de los pueblos indígenas en las políticas que les competen; incrementar la participación social y el ejercicio de los derechos de las personas con discapacidad; mejorar el acceso a la justicia, fortaleciendo la mediación como mecanismo colaborativo de resolución de conflictos, y aumentar la participación ciudadana

6 Los proyectos que se han desarrollado involucraron al Ministerio Secretaria General de la Presidencia en asociación con la Corporación Nacional de Desarrollo Indígena (CONADI) y el Ministerio Secretaria General de Gobierno, al Ministerio de Justicia en asociación con las Corporaciones de Asistencia Judicial, al Ministerio de Educación, al Servicio Nacional del Consumidor (SERNAC), al Servicio Nacional de la Discapacidad (senadis), al Servicio Nacional de la Mujer (sernam) y a la Municipalidad de Peñalolén. 
y control social de las mujeres a través de la formación de habilidades que fortalezcan sus organizaciones.

Otro programa que responde a la segunda prioridad de mayor financiamiento es el de Apoyo a la Innovación y Competitividad, con un total de I 8,6 millones de pesos para II proyectos y II acciones específicas (AGCID, 20I3). Una apuesta de la UE por una mejor inserción de Chile en el mercado internacional con un enfoque a la productividad e innovación. El Objetivo del Programa Innovación y Competitividad UE-Chile: Innovación con foco en pymes y regiones es mejorar la calidad e implementación de las políticas chilenas en innovación y competitividad, a través de la introducción de nuevos instrumentos y herramientas de apoyo.

Aunque la cooperación de la UE promueve el concepto del desarrollo a través de la cohesión social, la competitividad y la innovación, resulta difícil medir el impacto de la cooperación en términos cuantitativos, más allá del número de acciones de cooperación llevadas a cabo, y del monto de cooperación de la UE destinado a Chile en los períodos estudiados (2002-2006/ 2007-20I3). Pero existen acciones anteriormente mencionadas que sí dan cuenta del apoyo a la institucionalidad, como el intercambio de experiencias en materia de desarrollo social y formación de recursos humanos, que han permitido la creación de políticas públicas para luchar contra la desigualdad, hechos tangibles e importante fruto de la cooperación en Chile.
Se puede observar el importante crecimiento que ha tenido el pIB chileno a partir del retorno a la democracia, la aplicación de políticas neoliberales y la firma de acuerdos de libre comercio. Según los datos del Fondo Monetario Internacional (FMI), se estimó en 424.298 millones de dólares el monto total del PIB de Chile para 20I5, ajustado por poder de compra, cifra que en términos nominales alcanza 240.000 millones. La proyección para el 2020 sitúa el PIв per cápita en PPA de Chile en los 28.5I4 dólares. El producto interno bruto (PIB) per cápita en paridad de poder adquisitivo (PPA) para 20I5: Chile se sitúa a la cabeza de América Latina con una estimación de 23.564 dólares, y estima que en 2016 superaría los 24.000 (Roa, 20I5). Además, en 1987 el porcentaje de pobreza en Chile era de un 45,I\%, mientras que para 1996 era de un 23,2\% (Banco Mundial, 20I7).

Sin embargo, los indicadores de crecimiento económico y desarrollo chocan visiblemente con el alto nivel de desigualdad de Chile. La mala distribución de las rentas posiciona a Chile en la cola de los países de la ocDE en términos de desigualdad, inserción laboral, género, infraestructura, etc. Chile sigue siendo uno de los países de América Latina con una alta desigualdad, el ingreso del $10 \%$ más rico es 26 veces superior que el $10 \%$ más pobre (OCDE, 20I5) uno de los peores resultados de los países OCDE.

Además, para Chile uno de los mayores problemas es la falta de calidad en el empleo, que sigue ligado a un 
sector productivo que requiere escasa cualificación profesional. En definitiva, el modelo exportador de commodities sigue impidiendo una mejora en la calidad del trabajo, lo que también puede afectar a la tensión social (ort, 20II). Además, más del 40\% del decil más pobre no tiene contrato, por lo que sigue persistiendo un problema de empleo informal asociado a una desprotección laboral.

Si bien el desempleo no es un problema, hay que preguntarse quiénes son los que quedan fuera del mercado laboral. De acuerdo a la Encuesta CASEN, la tasa de participación de mujeres en el mercado laboral solo llega al $43,5 \%$, mientras que en 1990 era 32,5\%, (CASEN, 20II). En definitiva, el cambio no ha sido sustancial y se siguen manteniendo apartadas del exitoso modelo de crecimiento.

Igualmente, es preocupante la inactividad juvenil, sobre todo en los estratos de más bajos ingresos. El 35,4\% de los jóvenes entre 20 y 24 años, que pertenecen al decil más pobre de ingresos, se encuentra sin estudiar ni trabajar, en comparación con el 4,2\% de los jóvenes del decil más rico (CASEN, 20II). Esta visible exclusión social también está asociada a la falta de expectativas de movilidad social que normalmente se consigue a través del binomio: nivel de educación y mejor empleo. La desigualdad en el acceso a la educación es desalentador; si la cobertura de educación superior es del 62,9\% en el Io\% más rico de la población, en el
I0\% más pobre de la población solo alcanza el 2I,8\% (CASEN, 20II).

Los proyectos de la cooperación regional europea en Chile, como es el caso de EUROsociAL, han apuntado a apoyar el desarrollo inclusivo y generar cierta influencia en la creación de políticas públicas enfocada en reducir la desigualdad en el área del desarrollo social (Hernández, 20I7). A pesar de su mayor desarrollo en la región, Chile sigue siendo un país con brechas estructurales que representan obstáculos para su desarrollo. Por lo tanto, es de gran importancia que la cooperación de otras regiones del mundo, como la UE — a través de sus experiencias-, pueda seguir estando presente en el abanico de la cooperación oferente hacia Chile.

La promoción de la cohesión social ha sido implementada en Chile a través de diversos programas bilaterales y regionales de la Unión Europea, especialmente durante el período de cooperación 2007-2013. Pero en el caso de EUROsociAL, la cooperación técnica partió fuertemente en el año 2006, materializándose en diferentes áreas. Por ejemplo, en los años 2006 y 2007, 50 instituciones chilenas tomaron parte en 74 actividades, relacionadas con las temáticas de empleo, fiscalidad, educación y justicia, que reunieron un total de 400 participantes" (CELARE, 2008).

En la segunda fase del proyecto Chile ya ha realizado 122 actividades. Es un país que destaca en la participación de 
actividades de políticas sociales, gobernanza y empleo, ocupando el tercer lugar entre los I7 países que conforman EUROsociAL y cuarto lugar en otras actividades como justicia y seguridad (SIA, 20I7).

Por ejemplo, en cuanto a políticas de empleo, se puso en marcha el Programa + Capaz para insertar en el mercado del trabajo 300.000 mujeres y 150.000 jóvenes inactivos (EUROsociAL, 20I6). Este introduce competencias transversales ${ }^{7}$ para el empleo en la evaluación, capacitación y certificación de beneficiarios. Otra reforma importante en temas de salud ha sido en el Sistema Nacional de Sangre en Chile, para promover la donación altruista (EUROsociAL, 20I0, y Fernández y Gudiño, 2009: 123). En materia de justicia se han establecido protocolos de actuación para migrantes y víctimas de trata, mediación en procesos judiciales familiares y la asistencia jurídica con un protocolo para adultos mayores en Chile, en la llamada política de envejecimiento positivo, que además ha creado centros diurnos de asistencia para 150 personas, como proyecto piloto que debe escalar a nivel nacional, basándose en un modelo de Dijon, Francia (EUROsociAL, 20I0 y 20I6).

Para que un mayor número de mujeres se incorpore al mercado del

7 De acuerdo a Chile Valora, "las competencias transversales son competencias de conducta: comunicación, trabajo en equipo, resolución de problemas, iniciativa y aprendizaje permanente, efectividad personal, conducta segura y autocuidado". trabajo, es necesario que el Estado asuma el cuidado de adultos mayores, tradicionalmente delegado a las mujeres.

En cuanto al fortalecimiento institucional, en la primera fase de EUROsociAL se creó la Fiscalía Especial de Criminalidad Compleja para delitos de corrupción, crimen organizado y lavado de dinero. Además el Servicio de Impuestos Internos introdujo la administración del riesgo de cumplimiento, la detección de incumplimiento fiscal (EUROsociAL, 20IO).

Además, en el sector empleo se ha formado a técnicos que carecían de experiencia en levantar perfiles y competencias transversales (oficios que no siempre cuentan con formación formal) en el SENCE y Chile Valora ${ }^{8}$."El aumento de la capacidad institucional también se logra mediante la creación de herramientas y protocolos de actuación, como es el caso del Ministerio Público de Chile, que hoy tiene más capacidad para la persecución de delitos de trata de personas y pornografía infantil (Fernández y Gudiño, 2009: 123). También se ha apoyado al

8 Chile Valora es una Fundación que depende de la Presidencia y del Ministerio del Trabajo desde el 20ro, para generar metodologías, levantamiento de perfiles de cualificación y formación. En el directorio están representados 3 miembros de la Confederación de la Producción y del Comercio (CPC), 3 miembros de la Confederación Unitaria de Trabajadores (cut) y 3 miembros de los Ministerios del Trabajo, Educación y Economía. Es una instancia de diálogo social similar a las que ya existen en España y Reino Unido. 
Consejo para la Transparencia para la puesta en marcha de la iniciativa "Consejo en Línea", una plataforma virtual de interacción con la ciudadanía, y en materia financiera, la creación de un Sistema Integrado de Fiscalización del Sistema de Impuestos Internos, a partir de experiencias en Dinamarca, Francia, España y Reino
Unido, para evitar la evasión fiscal ${ }^{9}$ y realizar declaraciones voluntarias (EUROsociAL, 20I6).

9 El Banco Interamericano de Desarrollo (BID) estima que en América Latina "más de la mitad del potencial de recaudación del impuesto (sobre la renta de personas) se pierde a través de la evasión" (El País, 20I7).

\section{UN NUEVO HORIZONTE EN LA COOPERACIÓN UE-CHILE: DE RECEPTOR A SOCIO PARA EL DESARROLLO}

Chile fue el primer país de América del Sur que logró firmar un Acuerdo de Libre Comercio de cuarta generación con la Unión Europea, lo que representa un avance significativo en las relaciones. Sin embargo, el éxito del modelo chileno no es suficiente para garantizar un desarrollo económico constante y acorde con las necesidades del país.

A pesar de estas necesidades, en marzo de 2013 la Unión Europea oficializó su suspensión de dirigir Ayuda al Desarrollo a ocho países latinoamericanos de renta media alta. La llamada "graduación" de países se aplica mediante "criterios cualitativos (países considerados de renta media alta por el CAD de la OCDE y aquellos que excedan del I\% del pIB mundial), así como indicadores cuantitativos sobre las necesidades (vulnerabilidad, desarrollo humano, dependencia en la ayuda) y las capacidades (crecimiento del
PIB, inversiones extranjeras directas)" (Butkeviciene, 2010: 92). Esa decisión de "graduar" se explica por varias razones, en primer lugar, la UE priorizará en el próximo período de cooperación 20I4-2020, a los países menos desarrollados de la región (centroamericanos $\mathrm{y}$ andinos). En segundo lugar, la crisis económica y financiera que ha vivido el viejo continente hace más difícil la atribución de fondos para el desarrollo hacia países de renta media alta.

Una evaluación de los programas 2007-20I3 nos indica que en América Latina "se han mejorado las capacidades de las contrapartes, el acceso a los servicios y los cambios en políticas y regulaciones, además ha habido una transferencia de conocimiento y aprendizaje entre pares, tanto entre los países europeos y los latinoamericanos como de los latinoamericanos entre sî" (Comisión Europea, 20I4), por lo que hoy en día se puede decir que este aprendizaje se ha traducido 
en un empoderamiento mayor de los países latinoamericanos para buscar soluciones regionales a través de mecanismos como la cooperación sur-sur.

La política de cooperación de la Unión Europea para el período 20I42020 está teniendo un importante cambio en relación a los países beneficiarios, en particular en lo que respecta a América Latina, debido a la graduación de algunos países de la AOD en general, y aportada por la Comisión Europea en particular. Esta fue una decisión del Comité de Ayuda al Desarrollo (CAD) de la OCDE en 20I3, para los países que superaban los I2.700 USD de renta per cápita, tal y como calcula el Banco Mundial. La cooperación entre América Latina y la Unión Europea, para estos países graduados de la AOD — que para el año $20 I 7$ serían Chile, Uruguay y Antigua y Barbuda-, anuncia una nueva etapa de la cooperación de la UE en la región, cambiando prioridades y, por lo tanto, instrumentos de financiación. $\mathrm{Al}$ ser graduados durante el año 20I7, lo que buscan esos países definidos de renta media alta por su nivel de Producto Interno Bruto, es que su nivel de desarrollo sea reconocido tanto por la mirada de la riqueza nacional respectiva, como también por las diversas fuentes de vulnerabilidad estructural, como puede serlo la inversión y el ahorro, la productividad y la innovación, la infraestructura, la educación, la salud, la fiscalidad, el género y la lucha contra el cambio climático.
En la actualidad, Chile es uno de los ocho países que se gradúan de la cooperación bilateral europea, pero que sigue siendo un receptor de cooperación regional ${ }^{10}$ y triangular de la Unión Europea. Pero, aunque los países graduados puedan acceder a la financiación de los programas de ayuda regional de la UE a América Latina - como es el caso de EUROsociAL-, esta solo representa el I,2\% de los recursos totales y no tiene metas de desarrollo internacional, sino que más bien responde a estrategias de interés europeo (Sanahuja, 2010).

Por lo tanto, el programa EUROsociAl se mantiene como parte de la cooperación regional, el cual sigue siendo clave para mantener ayudas de la UE para superar unos desafíos sociales e institucionales que escapan a los esfuerzos nacionales. El trabajo entre pares ha resultado ser un medio mucho más eficaz que el trabajo en solitario. Chile está aprendiendo, reformando y replicando políticas de cohesión social en el país y en la región. Son pequeños avances que promueven el cambio y el cumplimiento de los objetivos del milenio.

Entre los programas de cooperación europeos, EUROsociAL es el único que tiene entre sus principios orientadores la promoción de la

10 Los programas regionales son: ALFA, ALBAN, EUROsociAL, AL-INVEST, @LIS, URB-AL, EUROsolar y otros más recientes en Ciencia y Tecnología, como ALCUENET y EULARINET, y en medio ambiente WATERCLIMA-LAC. 
cooperación sur-sur y triangular desde el año 2004, de ahí su importancia para que Chile pase a ser un oferente de ayuda al desarrollo y no solo un receptor (Hernández, 20I7). En la actualidad Chile es el quinto país en Cooperación Sur-Sur ${ }^{11}$ (css), que se define como "una herramienta de política exterior que a menudo tiene como objetivo respaldar la solidaridad política y apoyar coaliciones internacionales de los países emergentes y en desarrollo" (Sanahuja 20I6: 29).

Desde los años ' 90 , Chile ha sido un donante importante en la región, pero con el programa EUROsociAL ha sido capaz de realizar más actividades en los últimos años. Por ejemplo, se han materializado numerosas transferencias en otros ámbitos, como las políticas sociales en las que Chile ha realizado 23 actividades en la región como cooperación sur-sur y también triangular. Algunos ejemplos son: Apoyo para el diseño de la política nacional de atención del adulto mayor en Honduras, en conjunto con España; Asesoría especializada a Perú para apoyar el Plan Nacional de Empleo para la elaboración de los catálogos del SNCP y los procedimientos de

11 La css está basada en un paradigma de equidad y solidaridad desde su formulación, que deja de lado a la perspectiva asistencial de la cooperación norte-sur (CNS) y se centra en principios como liderazgo y apropiación nacional, soberanía e independencia nacional, igualdad y horizontalidad, no condicionada, no injerencia en los asuntos internos y beneficios mutuos (Lengyel y Malacalza, 20I2:I32). certificación de competencias; Apoyo a Honduras para el diseño normativo y operativo de Servicios de Atención a los participantes del Bono Io mil desconcentrados, en conjunto con Austria y Colombia (EUROsociAL, 20I7). Asimismo y de acuerdo a la Ficha País de EUROsociAL, el Servicio de Impuestos Internos (SII) ha asesorado a Uruguay para la elaboración de un manual de atención al contribuyente y ha compartido con Ecuador su experiencia en la reciente reforma tributaria (EUROsociAL, 20I6).

En lo que respecta a Cooperación Triangular (CTR), esta se refiere a la asociación entre un país de Renta Media oferente de cooperación con un país tradicional (Renta Media Alta), que juntos facilitan recursos para el desarrollo de algún país de Renta Media Baja (Lazo 2013: 373). Según el último informe de la Secretaría General Iberoamericana (SEGIB), Chile se posiciona como el primer cooperador de la región. Del total de los 90 proyectos en esta materia, Chile estuvo a cargo de un $39 \%$ de ellos, frente a un $16,7 \%$ y II, $1 \%$ de Brasil y Argentina respectivamente (SEGIB, 20I6).

Aunque este tipo de cooperación se contempla en el Acuerdo de Asociación de 2002, ha sido poco implementado por los países europeos y Chile para mejorar el desarrollo de los países de la región. Desde el año 2008 se intenta relanzar esta estrategia por parte de la Agencia Chilena de Cooperación Internacional (AGCID) con los donantes tradicionales en el 
país, sobre todo Alemania y España. Actualmente hay 19 proyectos triangulares, estos y muchos de los que ya se han cerrado, han sido acordados con estos dos países europeos.

Con Alemania, por ejemplo, se inician las experiencias de triangulación en el año 2005 , pero no es hasta 2007 que se crea el Fondo Bilateral de Triangulación Chile-Alemania, mediante el cual se financiaron alrededor de 17 iniciativas de cooperación y desde 2010 ha pasado a ser un fondo para toda la región, administrado por la Deutsche Gesellschaft für Internationale Zusammenarbeit (GIZ) por encargo del Ministerio Federal de Cooperación Económica y Desarrollo (BMZ) (AGCID, 20I7).

En el caso de España, desde el año 2009 se han desarrollado in proyectos $\mathrm{y}$ acciones puntuales triangulares y 3 proyectos bilaterales de apoyo al desarrollo nacional de Chile. En el 2010 se crea El Fondo Mixto de Cooperación Triangular Chile-España para financiar dichas líneas de acción y se dota con aportes de AECID $(70 \%)$ y AGCID (30\%), pero desde el año 2014 las aportaciones son paritarias $(50 \%$ cada uno) para ambos socios. Además, tiene una cobertura más amplia, ya que el Memorándum de Entendimiento considera la exploración de intercambios técnicos y científicos, formación y capacitación de especialistas, alianzas público-privadas para el desarrollo, ejecución de proyectos conjuntos de innovación y desarrollo tecnológico, entre otros (AGCID, 207). El fondo es administrado por la AGCID.
Como se ha mencionado, la UE está redefiniendo la modalidad de la cooperación triangular de manera muy lenta, pero de acuerdo al Plan de Acción de la Cumbre celaC-Ue de 20I5, se comprometieron a fomentar esta cooperación para fortalecer las asociaciones entre las administraciones públicas en diversas temáticas. Gracias a estos acuerdos, Chile ya cuenta con 3 proyectos triangulares de la UE con Centroamérica (SIECA) y Cuba (AGCID, 20I7).

En cuanto al Instrumento de Colaboración o Partnership, se enfoca en terceros países con un interés estratégico por su prominente papel en los asuntos globales, la economía y el comercio internacional, y la gobernanza mundial. Igualmente se centra en las nuevas relaciones que debe tener la UE con aquellos países, como Chile, que se han graduado de la cooperación bilateral. Los objetivos del IP son los de promover los intereses europeos, apoyando la dimensión externa de las políticas nacionales europeas (ej.competitividad, investigación y desarrollo, migraciones) y cooperando en superar los desafíos globales (ej. energía, seguridad, cambio climático y medio ambiente $)^{12}$. El IP también incluye

12 El Parlamento Europeo y el Consejo adoptaron un reglamento el II de marzo de 2014 para convertir el Instrumento de Cooperación con Países Industrializados (ICI) en Instrumento de Partnership con Países Terceros (IP). La financiación es de 954,8 millones de euros para el período 20I42020 https://ec.europa.eu/europeaid/funding/funding-instruments-programming/ 
cooperación en diplomacia pública y cooperación académica, a través del programa Erasmus+ con un aporte de 3 millones de euros para América Latina para proyectos Jean Monnet ${ }^{13}$.

Este instrumento financia proyectos de interés para la UE que son definidos en conjunto con los países destinatarios y en los que puede participar cualquier institución (fundación, ONG, etc.), inscrita en el portal de fondos concursables de la $\mathrm{UE}^{14}$. Por ejemplo,

funding-instruments/partnership-instrument_en en América Latina, y en particular Chile, el PI ha financiado proyectos para la protección de la Propiedad Intelectual, sobre todo para las pymes, por un valor de 5 millones de euros. También en la línea de protección al medio ambiente se han financiado proyectos de cooperación para el desarrollo de una aviación civil más amistosa con el medio ambiente y el cambio climático por un valor de 7 millones de euros ${ }^{15}$, y un diálogo político con actores políticos relevantes (ej. gobiernos locales) que trabajan en proyectos de Euroclima+.

\section{Conclusión}

Desde el año 2002 y hasta 2013 la Unión Europea ha invertido 4 billones de euros en la región, mejorando las condiciones de vida de los ciudadanos y fortaleciendo las instituciones y las políticas públicas. De 580 millones de personas en América Latina, unos 60 millones han salido de la pobreza. No obstante, todavía son muchos los desafíos que se presentan en una región tan desigual.

La reestructuración de la ayuda propuesta por la UE es contradictoria

13 Los proyectos Erasmus+ dedicados a la movilidad de estudiantes y docentes, se financian con 130 millones anuales de euros, de los cuales entre un $4 \%$ y $5 \%$ es para América Latina, es decir 6,5 millones que aporta el Instrumento de Cooperación al Desarrollo (ICD). Comisión Europea (20I6). Presentación en el Seminario Regional Erasmus+ para América Latina. 26-27 de septiembre Lima, Perú. al momento de analizar indicadores como el GiNi en un país como Chile, que demuestra un nivel de desigualdad de los más altos de Latinoamérica. La cohesión social ha sido en el último período de cooperación de la UE hacia Chile, una de las prioridades más emblemáticas y con resultados visibles, tanto de manera bilateral como regional.

A nivel bilateral, en el caso de Chile, el Acuerdo de Asociación pierde el capítulo sobre cooperación al desarrollo, por lo que la graduación se ha sometido a un intenso debate en las negociaciones de actualización del

14 https://www.welcomeurope.com/toolbox-eurofunding.html

15 https://eeas.europa.eu/delegations/chile en/r8359/Chile\%2oand\%2othe\%2oEU p:// europa.eu/rapid/press-release_IP-I6-3570_ en.htm 
Acuerdo y se espera crear un subcomité permanente de cooperación que fije las orientaciones de la cooperación entre la UE y Chile, en conjunto con el Comité de Asociación, al igual que se ha negociado con México y el MERCosur (O'Farrill, 20I7).

En un momento en el que se están discutiendo los procesos y modernización del Acuerdo, hay que reflexionar sobre cómo revitalizar y qué tipo de cooperación generar para luchar contra las desigualdades, promover las energías limpias y la diversificación económica. En este contexto de reestructuración de la cooperación, Chile pasa a transformarse en un socio de la UE para impulsar acciones de otro tipo, como por ejemplo de carácter triangular ${ }^{16}$, de acuerdo al último memorándum de entendimiento firmado entre ambas parte en la Cumbre UE-CELAC, en junio 2015 en Bruselas. Esta modalidad puede ser beneficiosa para Chile y otros países de la región en áreas de interés mutuo, ya que mejora las relaciones vecinales, por un lado, y consolida la imagen país con los países donantes, por el otro. Sin embargo, Chile sigue siendo uno de los países más desiguales de Latinoamérica, lo que implica la necesidad de mantener el rol dual que lo caracteriza, tanto como oferente de cooperación,

16 La Cooperación Triangular es definida como la cooperación realizada entre países en desarrollo (socio y beneficiario) con la participación de un tercer socio (donante). AGCI, 20I4. http://www.agci.cl/index.php/ cooperacion-sur-sur-y-triangular así como receptor en áreas donde las brechas estructurales siguen latentes.

En la nueva modalidad de cooperación regional destaca la cooperación sur-sur (Estrategia Regional 20I42020) en la que el programa EUROsociAL tiene un papel protagónico. La asesoría técnica de este programa ha permitido la mejora - e incluso creación - de programas y políticas públicas en todos los sectores: empleo, género, justicia, diálogo social, protección social, salud, seguridad ciudadana e institucionalidad democrática (Hernández, 20I7).

Como se ha mencionado, Chile es el principal país en la cooperación triangular en la región (SEGIB, 20I4). Su amplia experiencia con España, Alemania y otros socios tradicionales, demuestra su capacidad para seguir profundizando esta modalidad de cooperación con otros socios.

Desde el año 2016 la AGCID viene trabajando, al interior del CAD/OCDE, un aumento del foco en los desafíos particulares de los países de renta media alta, como la pobreza, desigualdad, protección al medio ambiente y el cambio climático. Se han denominado "países en desarrollo en transición" y buscan otro tipo de medición del desarrollo más multidimensional y no solo por criterios de la renta per cápita. La graduación de Chile significaría que no pueda acceder al sistema de créditos en condiciones ventajosas (blandos) otorgados por los bancos de los países donantes del CAD, con los que se han financiado, por ejemplo, proyectos 
energéticos. Tampoco podría acceder a cooperación técnica, transferencia de tecnología y buenas prácticas por parte de los miembros del CAD (modalidad de cooperación bilateral) (AGCID, 20I7b).

Los países en desarrollo en transición están negociando en varios encuentros de alto nivel al interior del CAD y es posible que en el futuro próximo se tengan en consideración sus demandas que ya han sido apoyadas por la UE, la CEPAL, el PNUD, el
Centro de Estadísticas del CAD/OCDE y el Centro del Desarrollo de la ocDE (AGCID, 20I7b y O'Farrill, 20I7).

Este nuevo contexto entre Chile y la UE debe permitir establecer otro tipo de cooperación, entre iguales, para el desarrollo inclusivo y sostenible de ambas partes, en un contexto donde el mundo está entrando en una nueva era del sistema de cooperación internacional con el establecimiento de los Objetivos Sostenibles para el Desarrollo.

\section{Bibliografía}

Agencia Chilena de Cooperación Internacional (AGCID) y Unión Europea, (20I3). "Cooperación Chile-Unión Europea 2007-2013. Promoviendo la Cohesión Social y la Innovación en Chile”.

Agencia Chilena de Cooperación Internacional (AGCID (20I7). Qué es la cooperación triangular. Disponible en: https://www.agci.cl/index.php/acerca-de-agci/330-que-es-la-cooperacion/ triangular

Agencia Chilena de Cooperación Internacional (AGCID (20I7b). Minuta de Mitigación de la Graduación de Chile por el Comité de Ayuda al Desarrollo de la OCDE (CAD). Septiembre 20I7.

Bretherton, Ch. y Vogler, J. (2006). The European Union as a Global Actor. Oxford: Routledge, segunda edición.

Butkeviciene, J. (2013). "The European Commission cooperation towards Latin America”. En: Arriola, S.; Garranzo,
R. y Ruiz Jiménez, L.. (Coords). La renovación de la cooperación iberoamericana. Transformaciones para una agenda post 2015 . Madrid: AECID, SEGIB.

CASEN. (20II). Ministerio de Desarrollo. Encuesta de caracterización socioeconómica nacional.

CELARE. (2008). "Cohesión Social: la clave del desarrollo”. Revista EUROLAT, №77, año I5, vol. 4. Diciembre.

Consejo de Europa (2004). A New Strategy for Social Cohesion. European Committee for Social Cohesion. Disponible en: http://www.coe.int

Comisión Europea (2016). Presentación en el Seminario Regional Erasmus+ para América Latina.26-27 de septiembre Lima, Perú.

Comisión Europea (2015a). Annual Report on the European Union's development and external assistance policies and their implementation. Disponible 
en: https://ec.europa.eu/europeaid/ annual-reports_en

Comisión Europea. (2015b). The European Union Explained: international cooperation and development. Disponible en: http://europa.eu/pol/pdf/flipbook/ en/development_cooperation_en.pdf Comisión Europea. (2015c). Plan de Acción Cumbre UE-CELAC 20I5, Bruselas. Disponible en: http://www.consilium.europa.eu/es/press/press-releases/20I5/06/II-eu-celac-summit-brusse1s-declaration/

Comisión Europea (20I4). Multiannual Indicative Regional Programme for Latin America. Development Cooperation Instrument 20I4-2020. EEAS, DG for Development and Cooperation.

Comisión Europea (2007). Country Strategic Paper Chile 2007-20I3, II.04.2007 (E/2007/6I5)

Durán, J.; Herrera, R.; Lebret, P. y Echevarría, M. (20I3). "La Cooperación entre América Latina y la Unión Europea. Una asociación para el desarrollo”. Santiago de Chile: CEPAL.

Fernández, A. y Gudiño, F. (2009). Reflexiones sobre el diseño, funcionamiento y resultados del programa EUROsociAL. En Carrillo, F., "La lucha contra la exclusión social en América Latina. Una mirada desde Europa”.La Paz: BID / EUROsociAL / Comisión Europea / Plural editores. pp. II3-I62.

Gómez, M. y Sanahuja, J.A. (1999). El sistema internacional de cooperación al desarrollo. Una aproximación a sus actores e instrumentos. Madrid: CIDEAL.
Hernández, B. (2016). Veinte años de cooperación europea en América Latina: hacia nuevas estrategias regionales. En Hernández, B. y Ruiz, L. (Comp.), América Latina y Chile en el sistema de cooperación del siglo xxI: el impulso a alianzas transformadoras. Santiago: RIL Editores, pp. 19-63.

Hernández, B. (20I7). El modelo europeo de Cohesión Social: intercambio de experiencias y aprendizajes a partir del programa EUROsociAL. En Hernández, B. y Gordín, J. (Comps.) Aprendizajes Políticos entre la Unión Europea y América Latina. Santiago: RIL Editores pp. 35-74.

Herrera, R. (20II). “El Pilar de Cooperación en el Acuerdo de Asociación Política y de Cooperación entre Chile y la Unión Europea”. Documento de Proyecto. CEPAL. AECID.

Lazo, C. (2012). Chile y la cooperación internacional: 20 años de experiencia (1990-2010). En Artaza, M. y Ross, C. (Eds). La Política Exterior de Chile, 1990-2009. Del Aislamiento a la integración regional. Santiago: RIL, pp. 367-396.

Martínez, I. y Sanahuja, J. (2009). La agenda internacional de eficacia de la ayuda y la cooperación descentralizada en España. Documento de Trabajo no 38 Fundación Carolina-CeALCI. Disponible en: http://biblioteca.hegoa.ehu. es/system/ebooks/I7924/original/Agenda_internacional_eficacia_de_la_ayuda_y_la_cooperacion_descentralizada_DT38.pdf 
O'Farrill, E. (20I7). Entrevista al Jefe de Departamento de la Cooperación bilateral y multilateral. AGCI. 28-II-20I7. OIT (20II). Informe del Trabajo Mundial. http://www.ilo.org/global/aboutthe-ilo/media-centre/press-releases/ WCMS_I66396/lang--es/index.htm

PNUD (2013). Informe de Desarrollo Humano. El ascenso del Sur: Progreso humano en un mundo diverso. Disponible en: http://www.undp.org/ content/dam/venezuela/docs/undp_ ve_IDH_20I3.pdf

Roa, T. (20I5). “Chile lidera el pıв per cápita de América Latina".El Economista América. Octubre Io. Dosponible en: http:// www.eleconomistaamerica.cl/empresas-eAm-chile/noticias/7067999/I0/15/ Chile-lidera-el-PIB-per-capita-de-America-Latina.html)

Sanahuja, J. (2007). “Cohesión Social: La Experiencia de la UE y las enseñanzas para América Latina”. Quórum, Revista de Pensamiento Iberoamericano. Madrid: Universidad de Alcalá. http:// www.redalyc.org/pdf/520/52001806.pdf Sanahuja, J. (2016). Nuevas Geografías, Agendas y Políticas: la gobernanza global del desarrollo en el escenario post 20I5. En; Hernández, B. y L. Ruiz Jiménez (comps). América Latina y Chile en el sistema de cooperación del siglo XxI: el impulso a alianzas transformadoras. Santiago: Editorial Ril.

Secretaría General Iberoamericana (SEGIB) (20I6). Informe de la Cooperación Sur-Sur en Iberoamérica. Disponible en: http://www.informesursur.org/
Secretaría General Iberoamericana (SEGIB) (20I4). Informe de Cooperación SurSur en Iberoamérica 20I3-20I4. Disponible en: http://segib.org/es/node/112 